DJS Vol. 41 (2020) 81 -91

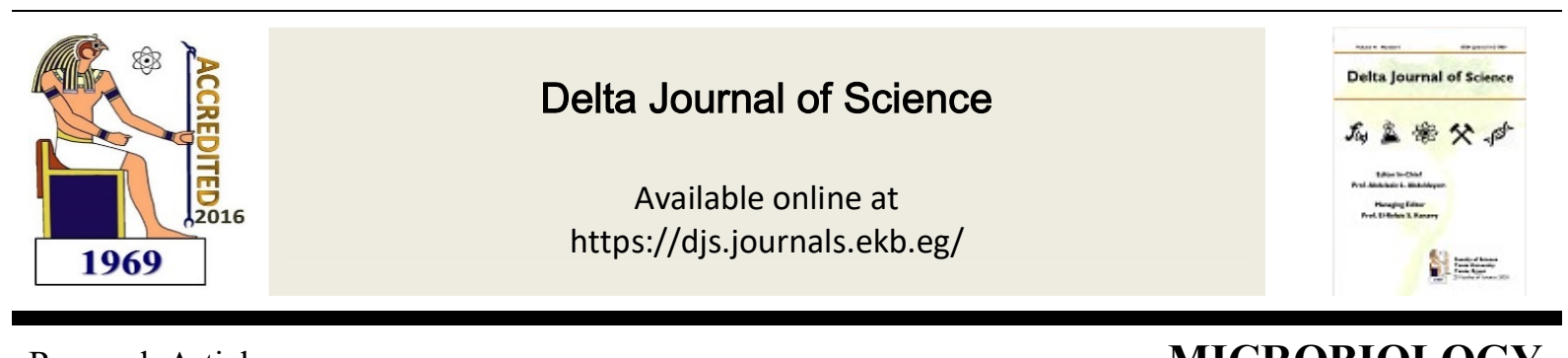

Research Article

MICROBIOLOGY

\title{
Phytochemical Screening and antioxidant activity of Chlorella vulgaris
}

\author{
Omnia Hamdy Abdel-Karim ${ }^{1}$, Saly Farouk Gheda², Gehan Ahmed Ismail ${ }^{3}$, Atef M. Abo-Shady ${ }^{4}$.
}

1 Teaching Assistant of Phycology, 2,3 Associate Professor of Phycology, 4 Professor of Phycology

\section{KEY WORDS}

Chlorella vulgaris,

Antioxidant, Total phenolic,

Phytochemical

compounds,

\begin{abstract}
Microalgae are rich sources of structurally novel and biologically active metabolites. Primary and secondary metabolites produced by these organisms which have drawn interest of the pharmaceutical industries. In this regard, the study aimed to screening of phytochemical compounds and evaluate the total phenolic content and the antioxidant activity of Chlorella vulgaris. The antioxidant activity of C. vulgaris was tested by 2,2-diphenyl-1-picrylhydrazyl DPPH radical scavenging method, reducing power assay and the total antioxidant capacity (TAC). The phytochemical screening exhibited the presence of alkaloids, flavonoids and phenols in all tested solvents which exhibited several biological activities. Among the different solvents, acetone extract exhibited the highest scavenging activity with (50.81\%). Also, showed reducing power activity estimated with $1.95 \mathrm{mg} \mathrm{AAE} / \mathrm{g} \mathrm{DW}$ and antioxidant capacity recorded $2.58 \mathrm{mg} \mathrm{AAE} / \mathrm{g} \mathrm{DW}$. In addition, considerable amount of the total phenolic has been detected in acetone extract recording $3.17 \mathrm{mg} \mathrm{GAE} / \mathrm{g} \mathrm{DW}$. The results revealed that there is a strong correlation between the antioxidant activity assays and the phenolic content of Chlorella vulgaris.

Thus, the green microalga Chlorella vulgaris in dietary supplements will be effective mediator in scavenging free radicals as it contains wide variety of bioactive compounds.
\end{abstract}

\section{Introduction}

Chlorella vulgaris is a Chlorophyceae unicellular freshwater or marine microalga. It is a good source of protein (60\%), lipids (20\%), chlorophylls and $\beta$ carotenes, soluble vitamins, choline, dietary fiber and essential minerals like iron, calcium, potassium, magnesium and 
phosphorous (Queiroz et al., 2011). It is acknowledged as good food source (Jong-Yuh and Mei-Fen, 2005). Beneficial effects of Chlorella vulgaris microalga has been reported for growth and building of body cells and development of children (Lee and Lee, 2002). The microalga is considered as a good antioxidant source, since it also contains extensive range of antioxidants and bioactive secondary metabolites (Aizzat et al., 2010)

Many studies have been performed to figure out the biochemical and physiological functions of Chlorella, such as promoting the growth rate of animals, boosting immune function, preventing stress-induced ulcers, antidiabetic and preventing high-fat diet induced dyslipidemia (Emami and Olfati, 2017). The effects of Chlorella, such as fatigue recovery, degradation of toxic materials, heavy metal removal, and environmental application were also studied (Jong-Yuh and Mei-Fen, 2005). Excess ROS may lead to an imbalance in its production and in the body's ability to detoxify or counteract the harmful oxidant effects of these free radicals (Finkel and Holbrook, 2000; Tiwari, 2001). The oxidative stress, which in turn result in oxidative damage of cellular components in the form of lipid peroxidation, protein denaturation or DNA conjugation finally cell death. (Mercuri et al., 2000) (Cam et al., 2003; Yavuz et al., 2003). Oxidative stress has been associated with many diseases like, and neural degradation, Parkinson's and Alzheimer disease, AIDS, and aging and cardiovascular diseases cancer (Cornish and Garbary, 2010). In recent times, studies suggest that there is an inverse relationship between dietary intake of antioxidant rich foods and the incidence of human disease. The search to replace these synthetic antioxidants with natural antioxidants has become an essential deed in immune pharmacy discovery since these components are suspected carcinogens (Goiris et al., 2012). Antioxidants are presumed to have several positive health effects that include prevention of different disease (Shibata et al., 2006). Microalgae in this regard are exceptionally rich source of pharmacologically active metabolites with antineoplastic, antitumor, antibacterial, antifungal and antiviral properties (Fedorov $\boldsymbol{e t}$ al., 2013; Emami and Olfati, 2017).

In addition, Microalgae as antioxidant providers for nutraceuticals and human wellness, and invoke the necessity of further exploring this great potential and their activity is probably related to the microalgae contain high content and diversity of antioxidant molecules (Sansone and Brunet, 2019).

In the present study, phytochemical screening for chemical identification of different bioactive components of $C$. vulgaris extracts using various solvents well be investigated. The antioxidant activity of the extracts will be estimated using different assays as well as the phenolic content will be also estimated and correlated to the antioxidant capacity. 


\section{Materials and methods}

\section{Cultivation of Chlorella vulgaris}

Axenic cultures of Chlorella vulgaris (Chlorophyta) was obtained from Phycology laboratory, Faculty of Science, Tanta University, Egypt. Identification of species was previously performed using morphological and taxonomical standard approaches according to (Desikachary, 1959; Prescott, 1962), Further confirmation was made using Algae Base (http://www.algaebase.org) as :Chlorella vulgaris Beyerinck (Beijerinck). The alga was grown on Kuhl's medium (Kuhl, 1964). The culture medium was sterilized in an autoclave at $121^{\circ} \mathrm{C}$ and $1.5 \mathrm{~atm}$ for 20 mins. After cooling, the microalga was cultured in a 21 Erlenmeyer flask and inoculated with $100 \mathrm{ml}$ of axenic freshly growing C. vulgaris inoculum under aseptic conditions. Then the cultures vessels incubated at $25 \pm 2{ }^{\circ} \mathrm{C}$ and illuminated using fluorescent light tubes at $80 \mu \mathrm{Em}^{-2} \mathrm{~s}^{-1}$. The cultures were aerated with air pump to accelerate algal growth and avoid its settling. The pumped air was sterilized first by passing through bacterial air filters of $0.45 \mu \mathrm{m}$ pore diameter. The biomass of algal culture was harvested at the end of exponential growth phase by centrifugation at $5000 \mathrm{rpm}$ (Fisher Scientific 225 Centrifuge) for 15 mins. The Cell pellets were rinsed three times and resuspended in sterilized distilled water to remove traces of growth medium followed by centrifugation at $5000 \mathrm{rpm}$ (Fisher Scientific 225 Centrifuge) for 15 mins after each wash. The collected biomass of $C$. vulgaris was then dried in oven at $50^{\circ} \mathrm{C}$, powdered by manual mortar and then stored in air-tight containers at $-20^{\circ} \mathrm{C}$ to be used in further experiments of the study.

\section{Determination of the growth parameter Optical density}

Growth of $C$. vulgaris was determined by measuring the optical density of the algal suspension at $560 \mathrm{~nm}$ with UV/Visible spectrophotometer (Fatma et al., 1994).

O.D. of the cultures was measured at regular interval of time (at 2 days interval).

\section{Preparation of Chlorella vulgaris extracts}

A known weight of $C$. vulgaris powder was extracted using (80\%) each of acetone, ethanol and methanol in addition to water for 72 hrs. in a shaking incubator (model: VS8480) under dark condition. Each solvent filtrate was concentrated to dryness under reduced pressure using Rotary Evaporator (IKA - RV 8 V) (10002170). weighed and stored in a sealed glass vials at $4^{\circ} \mathrm{C}$ in a refrigerator for subsequent experiments

\section{Phytochemical screening of Chlorella vulgaris}

Typical procedures described by Andima et al. (2014) were used for chemical identification of different phytochemical components of various extracts as follows:

Test for Alkaloids: $3 \mathrm{ml}$ of $1 \%$ of conc. $\mathrm{HCl}$ were added to $3 \mathrm{ml}$ of different extract on steam bath, then Wagner's reagent was added to the mixture. Turbidity of the resulting 
precipitate is an evidence for the presence of alkaloids.

Test for tannins: Equal volumes of the distilled water and different extracts were added to each other with stirring then add few drops of $\mathrm{FeCl}_{3}$. The formation of a green precipitate was an indication for the presence of tannins.

Test for saponins: $5 \mathrm{ml}$ of extract were shaken vigorously with $5 \mathrm{ml}$ of distilled water in a test tube and warmed. The formation of stable foam was taken as an indication for the presence of saponins.

Test for flavonoids: $1 \mathrm{ml}$ of extract was added $1 \mathrm{ml}$ of $2 \mathrm{~N}$ of $\mathrm{NaOH}$ solution. The formation of a yellow precipitate was taken as a positive test for flavonoids.

Test for terpenoids: $2 \mathrm{ml}$ of the extract were dissolved in $2 \mathrm{ml}$ of chloroform and evaporated to dryness. $2 \mathrm{ml}$ of concentrated sulphuric acid were then added and heated for about 2 mins. A greyish color indicates the presence of terpenoids.

Test for steroids: $2 \mathrm{ml}$ of extract were dissolved in $2 \mathrm{ml}$ of chloroform and $2 \mathrm{ml}$ concentrated sulphuric acid were added. Formation of a red color in the lower chloroform layer was used as an indicator for the presence of steroids.

Test for carbohydrate using Molisch's test: 3 $\mathrm{ml}$ of the extract were added to $2 \mathrm{ml}$ of Molisch's reagent and the resulting mixture shaken properly. $2 \mathrm{ml}$ of concentrated $\mathrm{H}_{2} \mathrm{SO} 4$ were then poured carefully down the side of the test tube. A violet ring at the interphase indicates the presence of carbohydrate.

Test for glycosides using Keller-Kiliani test: $2 \mathrm{ml}$ of each extract were dissolved in $2 \mathrm{ml}$ of glacial acetic acid containing one drop of $\mathrm{FeCl} 3$ solution. The mixture was then poured into a test tube containing $1 \mathrm{ml}$ of concentrated $\mathrm{H}_{2} \mathrm{SO}_{4}$. A brown ring at the interphase indicates the presence of a deoxy sugar, characteristic of cardenolides.

\section{Antioxidant assays}

\section{DPPH free radical scavenging assay}

DPPH free radical scavenging was determined according to the procedures described by Ul-Haq et al. (2012). In a glass tube, $2800 \mu 1$ of $0.1 \mathrm{mM}$ methanolic DPPH solution was mixed with $200 \mu$ l of test sample. Each sample was assayed in triplicate. The ampoules were overlaid, shaken well and kept away from the light at $37^{\circ} \mathrm{C}$ for 60 minutes. The tubes were centrifuged at $3000 \mathrm{rpm}$ for 5 mins after incubation. Then the change in color (from deep violet to light-yellow) of DPPH free radical was measured by taking the absorbance of the reaction mixtures at $517 \mathrm{~nm}$ on a UV/Visible spectrophotometer. Then, $3 \mathrm{ml}$ of $0.1 \mathrm{mM}$ of methanolic DPPH solution were used as a negative control while ascorbic acid was used as a positive control. The percentage scavenging of DPPH free radical for each concentration of test sample was calculated by using the following formula: 
\%Inhibition

$=$

\section{$\frac{\text { Absorbance of catrol -Absorbence of test sample }}{\text { Abrorbance of control }} \times 100$}

\section{Reducing power assay}

The method of Mohapatra et al. (2016) was used to assess the reducing power of different algal extracts. Aliquot $(1 \mathrm{ml})$ of different algal extracts was mixed with $2.5 \mathrm{ml}$ of a $0.2 \mathrm{M}$ sodium phosphate buffer $(\mathrm{pH}$ 6.6, prepared from $62.5 \mathrm{ml}$ of a $0.2 \mathrm{M} \mathrm{Na}_{2} \mathrm{HPO}_{4}$ and $37.5 \mathrm{ml}$ of $0.2 \mathrm{M} \mathrm{NaH} \mathrm{PO}_{4} \mathrm{H}_{2} \mathrm{O}$ ) and $2.5 \mathrm{ml}$ of $1 \%$ potassium ferricyanide $\left[\mathrm{K}_{3} \mathrm{Fe}(\mathrm{CN})_{6}\right]$ and incubated in a water bath at $50^{\circ} \mathrm{C}$ for 20 mins. Then, $2.5 \mathrm{ml}$ of the supernatant were then diluted with $2.5 \mathrm{ml}$ distilled water and $0.5 \mathrm{ml}$ of $0.1 \%$ ferric chloride solution. The intensity of the blue-green color was measured at $700 \mathrm{~nm}$ on a UV/Visible spectrophotometer. Results were expressed as $\mathrm{mg}$ of ascorbic acid/g dry weight (mg AAE/g DW). Ascorbic acid was used as standard and the test was carried out in triplicate.

\section{Total antioxidant capacity (TAC) assay}

The total antioxidant capacity (TAC) was determined by Ahmed et al. (2013). A test sample of $0.3 \mathrm{ml}$ of various extracts was mixed with $3 \mathrm{ml}$ of phosphomolybdenum reagent ( 28 $\mathrm{mM}$ sodium phosphate and $4 \mathrm{mM}$ ammonium molybdate in $0.6 \mathrm{M}$ sulphuric acid) in a capped vial. Incubation was then executed for 90 mins in a boiling water bath at $95^{\circ} \mathrm{C}$. After that, the samples were cooled at room temperature and the absorbance was measured at $695 \mathrm{~nm}$ against a blank (0.3 $\mathrm{ml}$ solvents without extracts). Ascorbic acid was used as reference and the result was expressed as $\mathrm{mg}$ ascorbic/g dry weight.

\section{Total phenolic content}

The total phenolic concentration was measured using the Folin-Ciocalteau method (Cox et al., 2010). In this protocol, $100 \mu 1$ of sample extract were mixed with $2.0 \mathrm{ml}$ of $2 \% \mathrm{Na}_{2} \mathrm{CO}_{3}$ and allowed to stand for 2 mins at room temperature. Then, $100 \mu \mathrm{l}$ of $50 \%$ FolinCiocalteau's phenol reagent were added. Incubation takes place for 30 mins at room temperature away from the light, then the absorbance was measured at $720 \mathrm{~nm}$. Gallic acid was used as a positive control. The total phenolic contents of the samples were expressed as mg Gallic acid equivalent per gram dry weight (mg GAE/g DW).

\section{Statistical analysis}

Statistical analysis was performed using IBM SPSS software package version 25, 2017 and the statistical methods used in SPSS were oneway ANOVA, two-way ANOVA, compare means in cross-tabulation and correlation. All the results were expressed as mean \pm standard deviation (SD). Significance was calculated at probability levels at $P<0.05$.

\section{Results}

\section{Growth curve of Chlorella vulgaris}


Biomass of $C$. vulgaris grown in modified Kuhl's medium was determined, as optical density at $560 \mathrm{~nm}\left(\mathrm{OD}_{560}\right)$ for 2 days intervals (Fig. 1). It is obvious that the stationary phase of $C$. vulgaris growth was started at $12^{\text {th }}$ day of the incubation. and the cultures were grown for 18 days.

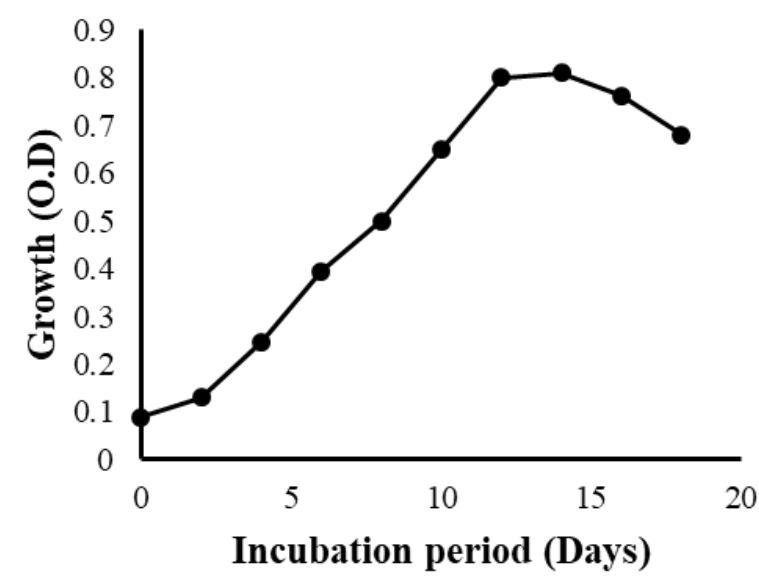

Fig.2.b.Growth curve of chlorella vulgaris grown in Khul's medium

\section{Phytochemical screening of Chlorella vulgaris}

Data in Table 1 revealed that tannins and terpenoids were not detected. and steroids were found only in C. vulgaris aqueous extract, while glycosides were detected only in both water and methanol extracts. Other major groups (alkaloid, phenols and flavonoids) of bioactive metabolites were detected in all solvents.
Table 1 Qualitative phytochemicals screening of different extracts of Chlorella vulgaris

\begin{tabular}{|c|c|c|c|c|}
\hline \multirow{2}{*}{$\begin{array}{l}\text { Microalgae } \\
\text { Phytochemicals/Extract }\end{array}$} & \multicolumn{4}{|c|}{ C. vulgaris } \\
\hline & $\mathbf{W}$ & $\mathbf{A}$ & $\mathbf{E}$ & $\mathbf{M}$ \\
\hline Alkaloid & + & + & + & + \\
\hline Pnols & + & + & + & + \\
\hline Flavonoids & + & + & + & + \\
\hline Tannins & - & - & - & - \\
\hline Glycoside & + & - & - & + \\
\hline Saponins & + & - & + & + \\
\hline Steroid & + & - & - & - \\
\hline Terpenoids & - & - & - & - \\
\hline
\end{tabular}

\section{Diphenyl-1-picrylhydrazyl (DPPH) radical scavenging activity}

As revealed in Fig. 2 the acetone extract of $C$. vulgaris showed the most scavenging activity with an inhibition percentage of $50.81 \%$, followed by the methanol extract with $39.40 \%$ while the ethanol extract recording the lowest inhibition recording $20.76 \%$.

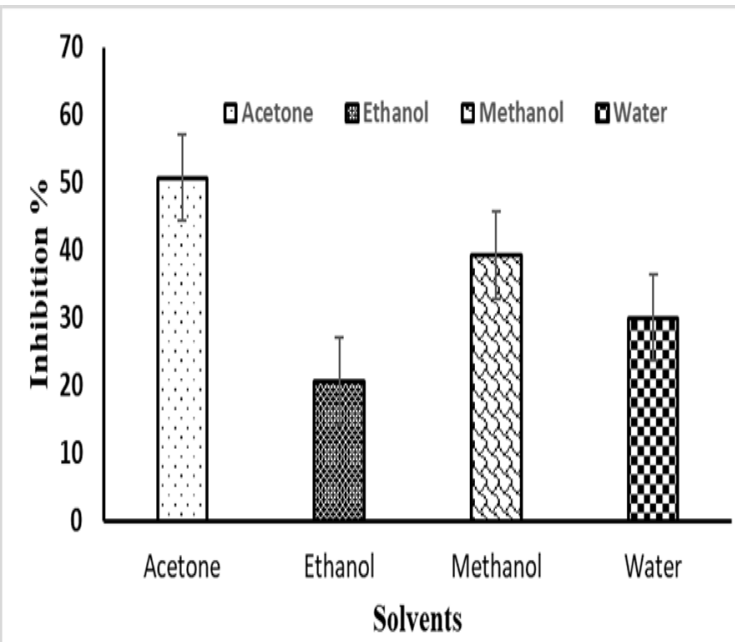

Fig.2 DPPH radical scavenging activity of different solvents of Chlorella vulgaris 


\section{Reducing power assay}

Results in Table 2 showed that, acetone extract of C. vulgaris showed the highest value among other solvents with $1.95 \mathrm{mg} \mathrm{AAE} / \mathrm{g} \mathrm{DW}$ followed by the methanol extract with $1.37 \mathrm{mg}$ AAE/g DW. While the ethanol extract showed the lowest activity with $0.67 \mathrm{mg} \mathrm{AAE} / \mathrm{g} \mathrm{DW}$.

\section{Total antioxidant capacity}

Data listed in Table 2 revelated that, the acetone and methanol extracts of $C$. vulgaris recorded significantly the best antioxidant capacity value of 2.58 and $1.94 \mathrm{mg} \mathrm{AAE} / \mathrm{g}$ DW, respectively. While the ethanol recorded the lowest capacity with $1.12 \mathrm{mg}$ AAE/g DW.

\begin{tabular}{|l|l|l|l|l|}
\hline \multicolumn{5}{|l|}{$\begin{array}{l}\text { Table 2. Total antioxidant capacity and reducing power activity of the } \\
\text { different extracts of Chlorella vulgaris }\end{array}$} \\
\hline Microalgae & \multicolumn{4}{|c|}{ C. vulgaris } \\
\hline Assay & \multicolumn{4}{|c|}{ Extract } \\
\cline { 2 - 5 } & Water & Methanol & Ethanol & Acetone \\
\hline $\begin{array}{l}\text { Reducing } \\
\text { Power } \\
\text { Activity (mg } \\
\text { AAE/g DW) }\end{array}$ & $1.07^{\mathrm{d} \pm 0.01}$ & $1.37^{\mathrm{c}} \pm 0.05$ & $0.67^{\mathrm{b}} \pm 0.01$ & $1.95^{\mathrm{a}} \pm 0.02$ \\
\hline $\begin{array}{l}\text { Total } \\
\text { Antioxidant } \\
\text { Capacity (mg } \\
\text { AAE/g DW) }\end{array}$ & $1.37^{\mathrm{d} \pm 0.0}$ & $1.94^{\mathrm{c}} \pm 0.01$ & $1.12^{\mathrm{b}} \pm 0.001$ & $2.58^{\mathrm{a}} \pm 0.00$ \\
\hline
\end{tabular}

\section{Total phenolic content (TPC)}

Results illustrated in Fig. 3 revealed that the total phenolic contents of various tested $C$. vulgaris extracts ranged between 0.65 to 3.17 mg GAE/g DW, and the acetone extract of $C$. vulgaris recorded the highest phenolic content of $3.17 \mathrm{mg} \mathrm{GAE} / \mathrm{g}$ DW compared to the other solvents. The lowest value was observed in the ethanolic extract recording $0.65 \mathrm{mg}$ GAE/g DW. Collectively, the correlation between TPC of different microalgae extracts and their antioxidant activity was evident as shown in Table 3

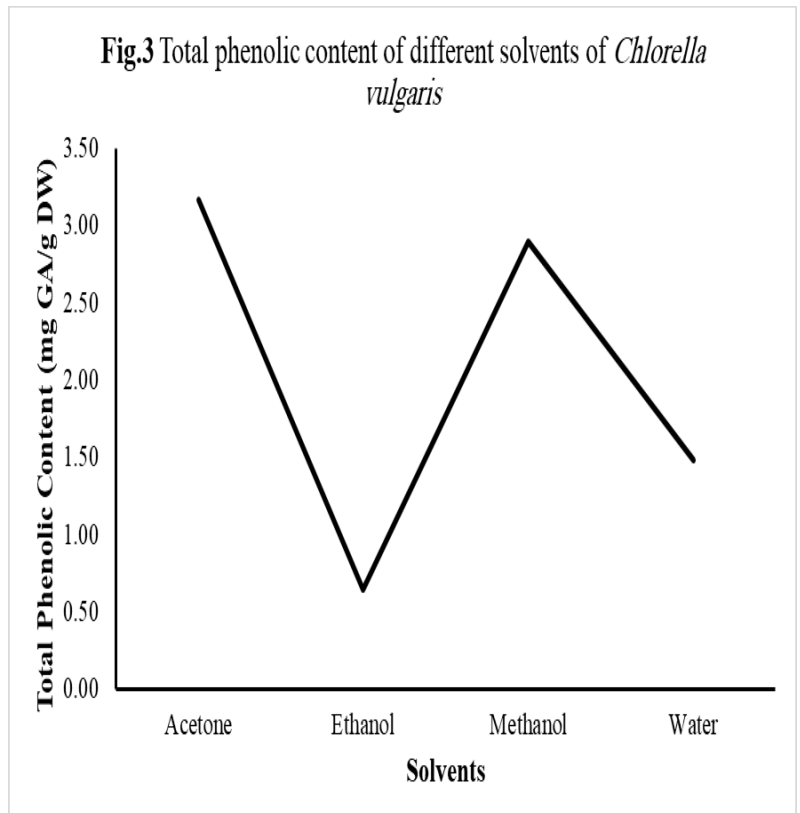

Table 3 Correlation values between total phenolic contents and antioxidant activities of different Chlorella vulgaris extracts

\begin{tabular}{ll}
\hline & \multicolumn{1}{c}{ Total phenolic content } \\
\cline { 2 - 2 } Antioxidant activities & \multicolumn{1}{c}{ C. vulgaris extract } \\
\cline { 2 - 2 } & \\
DPPH radical & $0.906^{*}$ \\
scavenging activity & \\
Reducing power activity & 0.850 \\
Total antioxidant & $0.900^{*}$ \\
capacity \\
\hline * Correlation is significant at the 0.05 level. \\
\hline
\end{tabular}




\section{Discussion}

In the human cells, reactive oxygen species (ROS) are formed by endogenous factors resulting in extensive oxidative damage, age related degenerative conditions and a wide range of other human diseases. Natural antioxidants from plant origin can react rapidly with ROS and retard the extent of oxidative deterioration (Gupta et al., 2018).

Furthermore, antioxidants from natural sources can also increase the shelf life of foods. Therefore, the consumption of antioxidant and addition of antioxidant to food materials could protect the body as well as the foods (Kumar and Pandey, 2013). Numerous compounds, such as some vitamins, carotenoids, and polyphenols (such as flavonoids), play a relevant role in preventing oxidative damages caused by free radicals by scavenging activity, and/or have a key role in the prevention of degenerative neuropathies or diabetes or in preventing cardiovascular diseases or cancers, as well as exerting anti-inflammatory, anti-viral, or anti-ageing activities (Wang et al., 2018). Microalgae would serve as a continuous and reliable source of natural products, comprising antioxidants because they can be cultivated in bioreactors on a large scale. Additionally, the qualities of microalgal cells can be controlled by using clean nutrient media for growing the microalgae avoiding use of herbicides, pesticides and any other toxic substances. The value of microalgae as a source of natural antioxidants is further enhanced by the relative ease of purification of target compounds (Amarowicz et al., 2004). In this connection different extracts of $C$. vulgaris found to have several phytochemical components which exhibited a wide range of the activity (Rajendran et al., 2014). Alkaloids have cytotoxic activity that is due to the presence of microtubule interfering agents that can bind to beta tubulin, thus inhibiting the formation of the mitotic spindle fiber required for cell division (Solanki et al., 2008). Flavonoids showed its presence in all tested extracts. Flavonoids have antimicrobial, antiviral, antioxidant and spasmolytic activity. Flavonoids have aroused considerable interest recently because of their potential beneficial effects on human health in fighting diseases. In general, phenolic compounds possessed specific physical, chemical and biological activities that make them useful as drugs. Phenolics were also responsible for the antimicrobial, anti-inflammatory, anti-viral, anticancer actions (Aliyu et al., 2009). Also, Phenolic compounds act as antioxidants by chelating metal ions, preventing radical formation and improving the antioxidant endogenous system (Dai and Mumper, 2010). Steroids are known to be important for insecticidal, antimicrobial, antiparasitic and cardiotonic properties. Steroids also play a vital role in nutrition, herbal medicine and cosmetics (Okwu, 2001).

Other compounds like saponins also have antifungal properties (Aboaba and 
Efuwape, 2001). Saponins are a mild detergent used in intracellular histochemistry staining to allow antibody access to intracellular proteins. In medicine, it is used in hyper cholestrolaemia, hyperglycemia, antioxidant, anticancer, antiinflammatory and weight loss, etc. It is also known to have antifungal properties. Saponins have been implicated as a bioactive antibacterial agent of plants (Mandal et al., 2005). The natural products derived from plant such as flavonoids, terpenoids and steroids etc., have received considerable attention in recent years due to their diverse pharmacological properties including antioxidant and antitumor activity (Paul, 2013).

Free radical scavenging ability of acetone extract of $C$. vulgaris recorded 50.8\% while another study reported methanol extract of $C$. vulgaris was maximum of $92.57 \%$ at 1000 $\mu \mathrm{g} / \mathrm{ml}$ (Jayshree et al., 2016).

It worth regarded that, the outcomes of reducing power, total antioxidant capacity of the studied $C$. vulgaris extracts showed great variation depending on the used solvent (Scaglioni et al., 2018).

In the present study the phenolic content obtained C. vulgaris was $3.17 \mathrm{GAE} \mathrm{mg} / \mathrm{ml}$ and this in agreement with the study of (Jayshree et al., 2016) who evaluated The total phenolic content in methanol extract $C$. vulgaris to be 2.20 GAE $\mathrm{mg} / \mathrm{ml}$.

These suggesting variation is based on extraction methods. Our results also indicated strong correlation (at $P<0.05$ ) between the antioxidant activity using DPPH, reducing power and TAC with the estimated total phenolic content of micro algal extract (Table 3). In the same line, (Zaid et al., 2015) demonstrated the antioxidant activity of the phenolic compounds present in C. vulgaris, Also, the results were in accordance to the data reported by (Jayshree et al., 2016). Also, (Sansone and Brunet, 2019) reported that, the microalgae considered to be the actual main source of antioxidants for human-derive from the combination of being photosynthetic, mainly unicellular and displaying high growth rate.

\section{Conclusion}

In this study different organic and water extracts of green microalga C. vulgaris showed a great variety of secondary bioactive compounds especially alkaloids, flavonoids and phenols. Also, great variation in their antioxidant potential particularly in acetone, methanol extracts. This antioxidant capacity was significantly correlated to their phenolic content Future studies are needed to evaluate the feasibility of $C$. vulgaris extract for developing potent antioxidant drugs and detect their biological activities.

\section{$\underline{\text { References }}$}

Aboaba, O. O., and Efuwape, B. M. (2001). Antibacterial properties of some Nigerian spices. Bioresearch Communications, 13, 183-188. 
Ahmed, D., Baig, H., and Zara, S. (2013). Seasonal variation of phenolics, flavonoids, antioxidant and lipid peroxidation inhibitory activity of methanolic extract of Melilotus indicus and its sub-fractions in different solvents. International Journal of Phytomedicine, 4(3), 326-333.

Aizzat, O., Yap, S. W., Sopiah, H., Madiha, M., Hazreen, M., Shailah, A., . . . Mohd Yusof, Y. A. (2010). Modulation of oxidative stress by Chlorella vulgaris in streptozotocin (STZ) induced diabetic Sprague-Dawley rats. Advances in Medical Sciences, 55(2), 281-288.

Aliyu, A., Musa, A., Sallau, M. S., and Oyewale, A. O. (2009). Proximate composition, mineral elements and antinutritional factors of Anisopus mannii N.E.Br. (Asclepiadaceae). Trends in Applied Science Research, 4, 68-72.

Amarowicz, R., Pegg, R. B., RahimiMoghaddam, P., Barl, B., and Weil, J. A. (2004). Free-radical scavenging capacity and antioxidant activity of selected plant species from the Canadian prairies. Food Chemistry, 84(4), 551-562.

Andima, M., Bernard, S., Owor, R., and Edward, A. (2014). Preliminary qualitative analysis of phytochemical constituents of the Endemic Aloe tororoana Raynolds in Tororo, Eastern Uganda. Global Advanced Research Journal of Agricultural Science, 3(3), 2315-5094.

Cam, M., Yavuz, Ö., Guven, A., Ercan, F., Bukan, N., and Üstündag, N. (2003). Protective effects of chronic melatonin treatment against renal injury in streptozotocin-induced diabetic rats. Journal of Pineal Research, 35(3), 212-220.

Cornish, M., and Garbary, D. (2010). Antioxidants from macroalgae: potential applications in human health and nutrition. ALGAE, 25(4), 155-171.

Cox, S., Abu-Ghannam, N., and Gupta, S. (2010). An assessment of the antioxidant and antimicrobial activity of six species of edible Irish seaweeds. International Food Research Journal, 17, 205-220.

Dai, J., and Mumper, R. J. (2010). Plant phenolics: Extraction, analysis and their antioxidant and anticancer properties. Molecules, 15(10).
Desikachary, T. V. (1959). Cyanophyta: Indian Council of Agriculture Research.

Emami, S., and Olfati, A. O. (2017). Effects of dietary supplementing of Spirulina platensis and Chlorella vulgaris microalgae on hematologic parameters in streptozotocin-induced diabetic rats. Iranian Journal of Pediatric Hematology and Oncology, 7(3), 163-170.

Fatma, T., Sarada, R., and Venkataraman, L. V. (1994). Evaluation of selected strains of Spirulina for their constituents. Journal of the Phycological Society, 33(2), 89-97.

Fedorov, S. N., Ermakova, S. P., Zvyagintseva, T. N., and Stonik, V. A. (2013). Anticancer and cancer preventive properties of marine polysaccharides: Some results and prospects. Marine Drugs, 11(12), 4876-4901.

Finkel, T., and Holbrook, N. J. (2000). Oxidants, oxidative stress and the biology of ageing. Nature, 408(6809), 239-247.

Goiris, K., De Vreese, P., De Cooman, L., and Muylaert, K. (2012). Rapid screening and guided extraction of antioxidants from microalgae using voltammetric methods. Journal of Agricultural and Food Chemistry, 60(30), 7359-7366.

Gupta, V. K. M., Shrivastava, R. K., and Singh, N. (2018). Status of exogenous antioxidant, total antioxidant capacity and oxidative stress in SCA patients. Indian J. Appl. Res, 8, 112-118.

Jayshree, A., Jayashree, S., and Nallamuthu, T. (2016). Chlorella vulgaris and Chlamydomonas reinhardtii: Effective antioxidant, antibacterial and anticancer mediators. Indian Journal of Pharmaceutical Sciences, 78, 575-581.

Jong-Yuh, C., and Mei-Fen, S. (2005). Potential hypoglycemic effects of Chlorella in streptozotocin-induced diabetic mice. Life Sciences, 77(9), 980-990.

Kuhl, A. (1964). Handling and Culturing of Chlorella. In D. M. Prescott (Ed.), Methods in Cell Biology (Vol. 1, pp. 159-187). New York and London: Academic Press.

Kumar, S., and Pandey, A. K. (2013). Chemistry and biological activities of flavonoids: An overview. The Scientific World Journal, 2013, 16.

Lee, Y., and Lee, H. (2002). Industrial uses of algae. Korean Journal of Applied 
Microbiology and Bioengineering, 15, 1924.

Mandal, P., Sinha Babu, S. P., and Mandal, N. C. (2005). Antimicrobial activity of saponins from Acacia auriculiformis. Fitoterapia, 76(5), 462-465.

Mercuri, F., Quagliaro, L., and Ceriello, A. (2000). Review paper: Oxidative stress evaluation in diabetes. Diabetes Technology \& Therapeutics, 2(4), 589-600.

Mohapatra, L., Bhattamisra, S., Panigrahy, R., and Parida, S. (2016). Evaluation of the antioxidant, hypoglycaemic and antidiabetic activities of some seaweed collected from the East Coast of India. Journal of Biomedical and Pharmacology, 9(1), 365-375.

Okwu, D. E. (2001). Improving the nutritive value of Cassava Tapioca meal with local spices. Journal of Nutraceuticals, Functional \& Medical Foods, 3(4), 43-50.

Paul, J. P. J. (2013). Phytochemical analysis of Padina distromatica Hauck. Indo American Journal of Pharmaceutical Research, 3(7), 5290-5297.

Prescott, G. W. (1962). Algae of the Western Great Lakes Area: 2nd ed. Wm. C. Brown Co., Dubuque, lowa 977 pp. .

Queiroz, M. L. S., da Rocha, M. C., Torello, C. O., de Souza Queiroz, J., Bincoletto, C., Morgano, M. A., . . . Calgarotto, A. K. (2011). Chlorella vulgaris restores bone marrow cellularity and cytokine production in lead-exposed mice. Food and Chemical Toxicology, 49(11), 2934-2941.

Rajendran, N., Selvan, K., Piriya, S., Logeswari, V., Eswaran, K., Tamilselvi, A., and Vennison, J. (2014). Phytochemicals, antimicrobial and antioxidant screening from five different marine microalgae. Journal of Chemical and Pharmaceutical Sciences, 78-85.

Sansone, C., and Brunet, C. (2019). Promises and challenges of microalgal antioxidant production. Antioxidants, 8(7), 1-9.

Shibata, T., Hama, Y., Miyasaki, T., Ito, M., and Nakamura, T. (2006). Extracellular secretion of phenolic substances from living brown algae. Journal of Applied Phycology, 18(6), 787-794.

Solanki, R., Khanna, M., and Lal, R. (2008). Bioactive compounds from marine actinomycetes. Indian journal of microbiology, 48(4), 410-431.

Tiwari, A. (2001). Imbalance in antioxidant defense and human disease: Multiple approach of natural antioxidant therapy. jouranal of Current Science, 81, 1179-1187. Ul-Haq, I., Ullah, N., Bibi, G., Kanwal, S., Sheeraz Ahmad, M., and Mirza, B. (2012). Antioxidant and cytotoxic activities and phytochemical analysis of Euphorbia wallichii root extract and its fractions. Iranian Journal of Pharmaceutical Research, 11(1), 241-249.

Wang, T.-y., Li, Q., and Bi, K.-s. (2018). Bioactive flavonoids in medicinal plants: Structure, activity and biological fate. Asian Journal of Pharmaceutical Sciences, 13(1), 12-23.

Yavuz, O., Cam, M., Bukan, N., Guven, A., and Silan, F. (2003). Protective effect of melatonin on $\beta$-cell damage in streptozotocin-induced diabetes in rats. Acta Histochemica, 105(3), 261-266.

Zaid, A. A. A., Hammad, D. M., and Sharaf, E. M. (2015). Antioxidant and anticancer activity of Spirulina platensis water extracts. International Journal of Pharmacology, 11(7), 846-851. 